\title{
New Media/Internet Research Topics of the Association of Internet Researchers
}

\author{
Ronald E. Rice \\ Department of Communication, University of California, Santa Barbara, California, USA
}

\begin{abstract}
This study summarizes prior reviews of new media and Internet research, and the growth of the term Internet in academic publications and online newsgroups. It then uses semantic network analysis to summarize the interests and concepts of an interdisciplinary group of Internet researchers, as represented by session titles and paper titles and abstracts from the 2003 and 2004 Association of Internet Researchers conferences. In both years, the most frequent words appearing in the paper abstracts included Internet, online, community, social, technology, and research. The 2003 papers emphasized topics such as the social analysis/research of online/Internet communication, community, and information, with particular coverage of access, individuals, groups, digital media, culture; role and process in e-organizations; and world development. The 2004 papers emphasized topics such as access; news and social issues; the role of individuals in communities; user-based studies; usage data; and blogs, women, and search policy, among others.
\end{abstract}

Keywords access, AoIR, communication technology, Internet research, online community, semantic network analysis

Along with the rapid diffusion of the Internet, and the constant development of new related technologies, applications, and uses, social science and humanistic researchers have taken up the challenge of trying to understand the social aspects of this communication and information network. In particular, the Association of Internet Researchers (AoIR) has experienced tremendous growth

Received 2 January 2004; accepted 30 November 2004.

I thank Matthew Allen, Nancy Baym, and Sheizaf Rafaeli for making available the program files from the 2003 and 2004 AoIR conferences, Marya Doerfel for her helpful comments, and Nancy Baym and three anonymous reviewers for suggestions.

Address correspondence to Ronald E. Rice, Arthur N. Rupe Professor, Department of Communication, University of California, Santa Barbara, CA 93106-4020, USA. E-mail: rrice@ comm.ucsb.edu; web site: http://www.comm.ucsb.edu/rice_flash.htm in membership, paper submission, and conference activities. In an attempt to characterize the concerns of these Internet researchers at this juncture in the development of the association, this article first provides some research context by summarizing prior relevant reviews of new media and Internet research, and the use over time of the term Internet in academic publications and online newsgroups. After describing the sample texts-the session titles and paper titles and abstracts from the 2003 and 2004 AoIR conferences - and the semantic network method, it then analyzes the primary issues and concept clusters of concern to this set of Internet researchers. Note that this study is not a review of Internet research theories or results (of which by now there are many). Rather, it attempts to indicate the current research agenda, at the word and concept cluster level, of one primary interdisciplinary group of Internet researchers, as a way to help identify the state of the field.

\section{COVERAGE OF NEW MEDIA AND INTERNET RESEARCH}

\section{Recent Trends in New Media Research}

Lievrouw et al. (2001) analyzed the new media research focus of the Communication and Technology division of the International Communication Association, such as the primary theoretical approaches and major lines of research. (Lievrouw \& Livingstone's edited handbook [2002] surveys a broader, multidisciplinary view of "new media.") They noted that communication and technology research, as compared with mass media research or interpersonal/group/organizational research, emphasizes point-to-point or networked interactions, for either interpersonal or group communication, for selective purposes rather than the "production, transmission and reception of general interest via mass channels" (p. 271). More recent new media research has shifted from the prior emphasis on effects or impacts to a greater concern with how social groups and institutions adapt, structure, and shape the 
development and use of communication technologies. A parallel shift has occurred, from primary concerns with the technological, economic, and behavioral aspects, to cultural and critical studies, social theory, and social history of communication technologies. The theoretical orientations of this work range from the macro, to middle-range, to micro levels of analysis. Primary macro-level theories are concerned generally with the information society, and policy and regulation of news media systems and institutions. Primary middle-range theories include diffusion of innovations, critical mass theory, social presence/media richness, social influence, adaptive structuration, social informatics, self-organizing systems, and sociotechnical systems. Primary micro-level theories deal with socialpsychological aspects, considering features of technology either as a source of communication or as a channel of communication.

Particularly promising directions of new media research, the authors suggest, include the many contexts and applications of computer-mediated communication (such as group decision support, distance education, MUDs and MOOs, collaborative learning, virtual communities), globalization (intelligent networks and the range of new technologies from communication satellites to mobile/wireless communication, transborder data flows), equity and political implications (digital divide, knowledge and information gap, social access), popular culture and use of technologies at home (domestication of technology, household and community adoption and use of new media), and mediated education (distance education, learning communities, technology-enhanced classrooms, multimedia content, peer interaction).

\section{The Internet in Disciplinary Reference Databases, 1985-2003}

Indeed, the field of communication is just one academic realm concerned with Internet. To provide a broader sense of the growth of Internet research, five major indexing and abstracting databases were searched for all documents with the word Internet in either the title or the abstract, from 1985 through 2003. (It takes some time for each year's entries to be collected, indexed, added, and made retrievable, and reference databases often retrospectively update their journal coverage, so searches on 2004 entries would not be valid until at least the middle of 2005, and would continue to change somewhat after that.) These were Business Source Premier (business and management), Library and Information Science, SOCIOFILE (sociology), CommAbs (communication journal abstracts), and Medline (biomedical publications). The keyword was combined with each subsequent year of publication to find the number of documents in that database that year. The number retrieved each year was divided by the total number of documents for the database across all years, to provide the relative coverage each year, allowing comparisons over time and across databases (which have very different numbers of documents).

Table 1 shows that the library/information science and business/management fields showed the earliest concern with the Internet, which makes sense given the broad practical implications of the Internet for business and

TABLE 1

Percent of titles and abstracts using the word Internet in five disciplinary databases, 1985-2003

\begin{tabular}{|c|c|c|c|c|c|}
\hline Year & $\begin{array}{l}\text { Business } \\
\text { source } \\
\text { premier }\end{array}$ & $\begin{array}{l}\text { Library \& } \\
\text { information } \\
\text { science }\end{array}$ & SocioFile & $\begin{array}{l}\text { Comm } \\
\text { abstracts }\end{array}$ & MedLine \\
\hline 1985 & .0 & & & & \\
\hline 1986 & .0 & & & & \\
\hline 1987 & .0 & & & & \\
\hline 1988 & .0 & .0 & & & \\
\hline 1989 & .0 & .0 & & & \\
\hline 1990 & .0 & .1 & & & \\
\hline 1991 & .0 & .2 & & & .0 \\
\hline 1992 & .0 & .4 & .0 & & .0 \\
\hline 1993 & .2 & 1.4 & .1 & & .2 \\
\hline 1994 & 1.0 & 4.7 & .6 & $3.4 / 3.2$ & .5 \\
\hline 1995 & 4.1 & 7.8 & 1.8 & $1.4 / 1.3$ & 1.3 \\
\hline 1996 & 7.8 & 9.7 & 4.7 & $2.7 / 2.6$ & 2.7 \\
\hline 1997 & 9.7 & 10.4 & 6.8 & $7.4 / 7.4$ & 4.2 \\
\hline 1998 & 9.7 & 10.3 & 8.9 & $12.2 / 11.8$ & 7.7 \\
\hline 1999 & 13.7 & 13.1 & 9.4 & $12.2 / 11.6$ & 14.0 \\
\hline 2000 & 21.5 & 12.3 & 14.7 & $11.2 / 12.2$ & 18.3 \\
\hline 2001 & 14.0 & 12.5 & 16.7 & $19.2 / 19.5$ & 18.0 \\
\hline 2002 & 9.1 & 9.3 & 21.9 & $16.8 / 16.7$ & 16.6 \\
\hline 2003 & 9.3 & 7.8 & 14.4 & $13.4 / 13.7$ & 16.4 \\
\hline Total & 198,000 & 17,873 & 2048 & $582 / 621$ & 17,474 \\
\hline
\end{tabular}

Note. Search term = "Internet"; search fields = default, typically title and abstract (except abstract only for CommAbs), English language; search date $=$ November 28,2004 . Values are yearly percent of total retrievals for that database. ".0" indicates some articles were retrieved, but less than .1\% of Total. Business Source Premier: 8000 business, professional, trade sources. Library and Information Science: journals, conference proceedings, book reviews, research reports, unpublished research. SocioFile: 1700 sociology journals, and books, chapters, dissertations, book reviews. CommAbs: from CIOS database of communication journal, report, and book abstracts; not all journals included from 1985 on. Second percents and total are for the search term Internet and "world wide web" to correspond to Kim and Weaver's (2002) study. Medline: 4600 biomedical journals. 
information management (especially library networking and organizational transactions). The biomedical field was a little later in developing an interest in the Internet, with the more social science-oriented sociology and communication fields even later. Although it's difficult to tell how the percentages for 2002 and 2003 will eventually stabilize with retrospective updates of the databases, it seems that relative interest in the Internet (specifically labeled) has declined in the more applied areas in the past 2 years.

Using a similar technique several years ago, Kim and Weaver (2002) searched for both Internet and World Wide Web in Communication Abstracts from 1996 to 2000. They found a total of 561 articles in 86 communicationrelated journals and Internet-related books, with the following percentages for each year: $2.3 \%, 5.0 \%, 7.2 \%$, $8.4 \%$, and $7.5 \%$. (Note that even with the additional search term, these percentages are noticeably lower than the recent search results in Table 1 , indicating how the same database can generate different results at different times, due to added entries and journals.) They then coded each of these retrieved articles according to journal, publication year, research focus, development phase of research agenda, research method, and theoretical application. The most frequent research focus was law and policy $(22.5 \%)$, followed by uses and perception (18.9\%), economic (13.7\%), and politics/democracy/development $(10.2 \%)$. The articles revealed concern with all four phases of research development, but more with the first two phases (issues of the Internet itself, 33\%, and uses and users, $45 \%$ ), than the last two (effects, $12 \%$, and Concerns about improving the Internet, 11\%). Research methods used were primarily nonquantitative (72.9\%). Only $17.1 \%$ referred to one or more specific communication theories: uses and gratifications, democratic theory, information processing, diffusion, and development/dependency.

\section{The Internet in Newsgroups}

Online Usenet Newsgroup names also indicate recent and pervasive interest in the Internet. Searching the MSR Netscan program with the term Internet provided the number of newsgroups with the word Internet in them, and the number of postings to each of those newsgroups, from 1999 on (http://netscan.research.microsoft. com/Static/Default.asp; search on November 30, 2004). The number of newsgroups and the number of postings to those newsgroups grew from 436 newsgroups $/ 215,803$ postings to newsgroups in 1999 , to $878 / 998,001$ in 2003 , to $1040 / 643,086$ as of November 2004 (not a full year yet).

\section{ANALYZING TOPICS OF THE CONFERENCE OF THE ASSOCIATION OF INTERNET RESEARCHERS}

Given both this broad developing interest in Internet research in a variety of disciplines and media over the past decade, and promising research areas in both communication and interdisciplinary studies, the conference of the Association of Internet Researchers (AoIR) provides a good context for identifying the current research agenda. Especially for a developing research field, a central, interdisciplinary conference is a valuable venue for presenting new research, often previewing what will appear in refereed journals in the coming year. Further, papers reviewed and accepted by interdisciplinary peers are to some extent evaluated as being both relevant and rigorous.

\section{Sources and Sample}

The initial motivations, participants, and organization of the Association of Internet Researchers is nicely described by Steve Jones (2004) in the Consalvo et al. (2004) edited collection of top papers and keynote addresses from the first three AoIR conferences. Jones notes that even in the late 1990s, each separate academic discipline had not yet shown much interest in research about the Internet and the Web. The participants at a small conference in Des Moines, IA, in late 1998, where Jones first thought about such an association, came from a wide variety of disciplines, indicating that a separate, interdisciplinary association would be not only appropriate but also necessary. He emphasized that the original and continuing mission of AoIR reflected a "spirit of inclusiveness, curiosity, interdisciplinarity, and openness." Quickly, there were meetings at the National Communication Association, the development of the air-1 distribution list (as of November 2004, there were more than 1400 subscribers), and the first AoIR conference at University of Kansas in September 2000, drawing more than 250 people from 20 countries. The second AoIR conference was in Minneapolis, the third in Maastricht, the Netherlands, the fourth in Toronto, Canada, and the fifth in Brighton, UK.

To portray a detailed profile of topics considered in the 2003 and the 2004 AoIR conferences, the session titles and the titles and abstracts of the accepted papers (approximately 320 in both 2003 and 2004, not including panels that did not have separate papers) were analyzed to identify the most frequent terms, and the associated semantic clusters, representing research interests of the conference participants. In 2003, the conference organizers took all submitted abstracts (some in French) and produced shorter versions of nearly equal length, all in English, and posted those shorter paper abstracts and the paper titles on the AoIR web site. In 2004, the conference organizers posted the authors' full-length abstracts and the paper titles on 
the AoIR web site. By analyzing the session titles, paper titles, and paper abstracts, we can obtain a multilevel view of AoIR research topics.

This use of the conference session titles, paper titles, and paper abstracts makes a fairly reasonable assumption concerning "meaning" at different levels. Conference organizers group papers by similar topics, where possible, and develop labels for that group of papers, to use as the session titles. This represents an informal content analysis of the underlying themes of each set of papers. Paper titles represent an informal content analysis of research themes. It's reasonable to assume that authors attempt to choose both the title wording and the abstract wording to succinctly but validly reflect the main topic(s) of the paper. Other approaches are possible, such as professional abstracting, or more formal content analysis of the abstracts or even the full text. But each of those approaches is removed in one way or another from the authors' original intent. It's reasonable to assume that authors are the best judge of what it is they want to convey through their titles and abstracts. Certainly conference attendees use the session titles and paper titles to make quick judgments as to which sessions they want to attend, and which papers they might want to obtain.

\section{Semantic Network Analysis}

The essence of semantic network analysis is rather straightforward (Danowski, 1988). Text is analyzed to determine some measure of the extent to which words are related, which indicates something about their meaning. One measure of this relationship is the extent to which word pairs co-occur within a given meaning unit. Then, this measure of relatedness across a set of words is used to group, cluster, or scale the words (or some subset, such as the more frequently used words). These clusters can be directly interpreted, or used to derive more quantitative measures for use in other analyses, or bases for formal content analysis.

Semantic network analysis has some useful benefits. First, it analyzes the natural text of respondents, rather than abstracted indicators such as a priori content categories. Second, it identifies emergent clusters of potential meaning. That is, it analyzes relations and distinctions among words rather than frequencies of individual words removed from their semantic context. Third, while it can be used on single texts, as can quantitative content analysis and qualitative approaches such as semiotic, rhetorical, or hermeneutical methods, it can also be used to identify global structures across large samples of text. Fourth, in some manifestations, it can automate large portions of what would otherwise be a difficult text management problem. And fifth, it allows the integration of qualitative (tex- tual) and quantitative (numeric measures of usage or effects) approaches.

Network approaches have been applied to the study of semantic memory and association processes (Chang, 1986; Collins \& Quillian, 1969; Flores-d'Arcais \& Schreuder, 1987), information retrieval algorithms and systems (Savoy, 1992), citation analysis (Callon et al., 1983; Danowski \& Martin, 1979; Lievrouw et al., 1987; Rice \& Crawford, 1992), content analysis of traditional and computer-mediated communication (CMC) media (van Cuilenburg et al., 1986; Danowski, 1982), and responses to open-ended survey questions (Carley \& Palmquist, 1992; Rice \& Danowski, 1993). Semantic network analysis using CATPAC has been applied to understanding positioning of candidates and issues in presidential debates (Doerfel \& Marsh, 2003) and the structure of interests in the International Communication Association (Doerfel \& Barnett, 1999), among other topics. These and other prior studies provide the underlying arguments about representing cognition and meaning through content associations.

\section{Semantic Network Analysis Approach}

The CATPAC program (Woelfel, 1991) used for this analysis counts the number of times any word occurs within each "meaning unit," and the number of times any two words co-occur within a "meaning unit." Here, the meaning unit in each respective analysis was the session titles, the paper titles, or the paper abstracts. In the current data, these meaning units are identified by the CATPAC delimiter " -1 " entered by the researcher (that is, the CATPAC default value of a 7-word wide sliding window was not used). From each of these data sets, the program produces a frequency list of the most frequent unique words (first using the default maximum of 160 words, and then a smaller set designed for a more focused analysis). The program excludes nonsubstantive "stop" words such as $a$, an, the, etc., and drops words that only occur once. The frequency listing of each unique word in each complete file was then inspected for variations on the same word, and all variations were changed to a common form (i.e., "effect" and "effects," "communication" and "communicate," "community" and "communities," etc.).

Then the program creates a co-occurrence matrix, where the value in each cell of the matrix is the number of times each pair of words occurs together within the meaning unit (the paper title or the paper abstract), summed across all units. The program then applies hierarchical clustering (here, the default Ward's method was used) to the respective co-occurrence matrices to identify clusters of words at any given clustering threshold in the resulting visual representation of cluster differences, called a dendogram. Peaks in the dendogram represent central 
clusters, while valleys between the peaks represent divisions between clustered words at any given threshold. For this study, the cutoff thresholds were chosen based on the interpretability of the resulting semantic clusters. When useful, both a specific cutoff level and a general cutoff level were chosen, to reflect both specific research themes as well as more general ones. The co-occurrence matrices involving a manageable number of words were also scaled and plotted via multidimensional scaling, to visually show how clusters of words are more or less "close" to each other in terms of the overall patterns of co-occurrence.

\section{RESULTS}

\section{Conference Themes}

To some unknown extent, each AoIR conference's advertised theme will influence that conference's titles, content, and orientation of submitted papers. The 2003 conference theme (taken from the web site, www.aoir.org) was Broadening the Band: "Though the Internet has become an integral part of the daily existence of many cultures worldwide, we have only begun to understand the ways in which it transforms our interactions, our knowledge, and our selves. Research on the Internet is a growing part of academic work, and it cuts across a wide variety of disciplines. AoIR was formed out of a recognition of the need to bring together people from diverse academic and cultural perspectives in order to advance collective understanding of the impact of this technology on contemporary life." The 2004 theme was Ubiquity: "The Internet seems to be at once everywhere and invisible but simultaneously it structures only a fraction of the communications of the total global community. It can facilitate greater interaction, understanding and political activism; being used at the same time to exclude, destroy and exploit. The much cited ubiquity of the Internet needs to be examined in both the contexts in which it is accepted and those in which it is contested."

\section{Session Titles-2003}

Table 2 lists the most frequently used words of the session titles for each conference. For the 2003 conference, organizers used quite detailed and descriptive session titles, each one attempting to capture the topics of its constituent papers. Based on the most frequent words, the 2003 AOIR conference emphasized the obvious topics: (a) Internet and online network and media research; (b) community (real and virtual); (c) communication; (d) identity and self; (e) digital divide, access; (f) governance; (g) knowledge and learning; and $(\mathrm{h})$ health and policy. The session titles noted the specific "new" technology of blogs. Other topics receiving less specific use in session titles included a wide range of social and political issues, such as (i) citizen, civic,

\section{TABLE 2}

Most frequent words, and semantic clusterings of 160 most frequent words, in session titles from AoIR 2003 conferences

6 or more times (number and percent): Internet $(34,9.3)$, online $(12,3.3)$, network $(10,2.7)$, research $(10,2.7)$, community $(9,2.5)$, identity $(8,2.2)$, digital $(6,1.6)$

5 times (1.4\% each): divide, governance, method, practice

4 times (1.1\% each): access, blog, broadening, critique, health, investigation, knowledge, learning, media, nation, perspective, policy, self, web

3 times $(0.8 \%$ each): communication, information, mediated, regulating, theory, virtual, world

[digital access]

[[resistance] [business loyalty]

[[blogs \& anonymity] [broadband access \& art] [commodification] [indigenous] [expanding boundaries] [copyright \& ethics] [localism \& democracy] [east Asian citizen] [foreign dialogue]]

[e-presence \& freedom]

[[belonging/linking] [gender \& culture histories]]

[[future events] [home] e-governance \& e-health]]

[[click \& mortar] [computer-based learning] [flows of information]]

[body \& ideology]

[game (online) consumption]

[[ecology] [work environment]]

[[ethics] [machine]]

[regulation/law \& liberty]

[[knowledge management] [cyberspace \& dotcoms]]

[computer expertise \& competence]

[surveillance]

[domestic \& marriage politics]

[civic engagement]

[mediated self]

[[identity \& media] [international perspective]]

[elections]

[research methods]

[virtual community]

[wireless elites]

[[disability policy] [www evolution]]

Note. Hierarchical semantic clusters are marked by brackets, at two cutoffs-more general [external brackets], and more specific [internal brackets].

democracy; (j) control and surveillance; (k) activism, resistance, dissent; (l) education, environment, politics; (m) gaming and collaboration; and (n) broadband and wireless.

Semantic clusters of the 160 most frequent words from the 2003 session titles include: (a) digital divide, access; (b) blog, communication critique; (c) e-government and e-health; (d) virtual community; (e) identity and learning; (f) research methods; (g) mediated networks; and 
(h) WWW policy and practice. A multidimensional scaling of these most frequent themes (along with the cluster dendograms, not shown for session title analyses, due to page limitations) indicates that access, digital divide, and educational aspects of Internet/online networking represent one cohesive, distinct conference theme. Two other distinct themes were network research and methods, and virtual community. The remaining themes were somewhat interrelated, ranging from policy/identity/performance, to health/governance/nation/world.

\section{Paper Titles-2003}

Table 3 lists the most frequently used words of the paper titles, which emphasized many of the more general session title themes, while also identifying more specific themes. Additional emphases included discourse/ participation, cyberspace/web sites, distance education, design/art/performance, and home/group/work/roles.

Semantic clustering of the paper title words identifies a range of major themes. These include: (a) copyright law; (b) work movement; (c) infrastructure; (d) free resources; (e) assessing information and communication technology (ICT); (f) home history; (g) contexts and studies of gender, global, democracy, web sites; (h) dialogue and coverage of science, medical, religious, resistance, foreign content; (i) games and roles; (j) surveillance; (k) blogs; (l) computer development and impacts; (m) mediated self; (n) learning (face and mediated); (o) network tools; (p) macro issues: social, divide, political, environment, education, participation, policy; (q) public issues (study and analysis of politics, technology discourse, practice, virtual identity); and (r) the broad and general theme of Internet (research community, ethics, management, design, culture, media).

As an example of visually portraying the relationships among semantic clusters, Figure 1 shows a multidimensional scaling of the clusters from the 40 most frequent words. These include: (a) politics and analysis; (b) discourse and knowledge; (c) education and gaming; (d) society and space; (e) computers and virtual development; (f) participation and the political world;

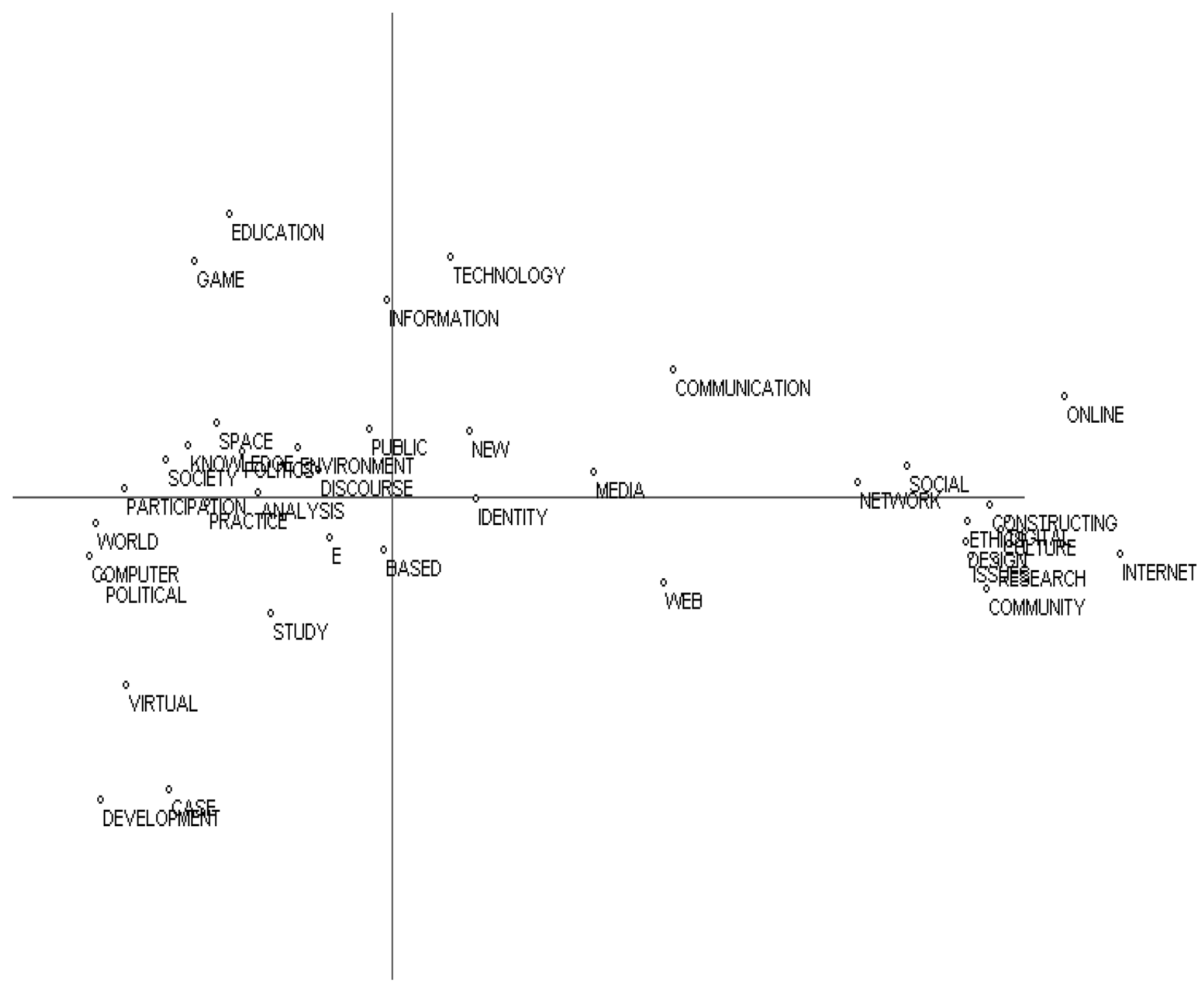

FIG. 1. Two-dimensional scaling of 40 most frequent words from 2003 conference paper titles. 
TABLE 3

Most frequent words, and dendogram/semantic clusterings of 160 most frequent words, in paper titles from AoIR 2003 conference (clusters marked by horizontal bars)

11 or more times (number and percent): Internet $(87,7.7 \%)$, online $(54,4.8 \%)$, community $(38,3.4 \%)$, social $(31,2.7 \%)$, digital $(24,2.1 \%)$, network $(23,2.0 \%)$, communication $(20,1.8 \%)$, culture $(20,1.8 \%)$, web $(19,1.7 \%)$, media $(16,1.4 \%)$, new $(16$, $1.4 \%)$, information $(15,1.3 \%)$, public $(15,1.3 \%)$, research $(15,1.3 \%)$, technology $(14,1.2 \%)$, identity $(13,1.1 \%)$, based $(12$, $1.1 \%)$

11 times (1.0\%): design, ethics, issues

10 times $(0.9 \%)$ : discourse, practice, society, space, study,

9 times $(0.8 \%)$ : analysis, case, constructing, education, environment, knowledge, politics, virtual

8 times $(0.7 \%)$ : computer, development, game, participation, political, world

7 times (0.6\%): age, blog, com, cyberspace, divide, mediated, perspective, policy, users

6 times $(0.5 \%)$ : assessing, distance, health, impact, learning, life, movement, role, software, trust

5 times $(0.4 \%)$ : art, chat, cross, effects, everyday, face, governance, government, home, Japan, line, net, open, resources, self, sphere, surveillance, theoretical, uses

4 times $(0.4 \%)$ : accessibility, capital, citizen, control, data, democracy, domestic, global, group, implications, language, local, national, place, privacy, real, regimes, strategies, time, tool, towards, usage, web sites, work

3 times (0.3\%): agenda, American, applying, civil, code, collaboration, competence, content, context, copyright, counter, dialogue, economic, electronic, empirical, exploring, first, foreign, forum, free, gender, history, icann, ict, im, indymedia, infrastructure, international, law, look, management, meaning, medical, methods, mobile, mobilization, multiple, organization, patterns, peer, possibilities, post, process, quality, religious, resistance, rural, science, sense, sims, smart, socio, south, structure, surveys, technical, testing, tools (remaining words not displayed)

A L T C S S F I U L G L N C J A A E P P M S C L R M I M W C D O I R U F $\mathrm{T}$ R A C I P C O I R T U I C S A R O A I A G P L O R O I O A E E M O O O O R N U S R O E S A C O C O M O R R R A A N O C T V P E P E S O B M P W A A. V R L M G F R E E O S S P T S E K E S U V S N G G U A I I A N L C T C I S Y . L N. E K L E A R A S E L O E I . S S. S C E T N E U P O L N D Y T. E L R. . I . M. A S N A L . S U S T I

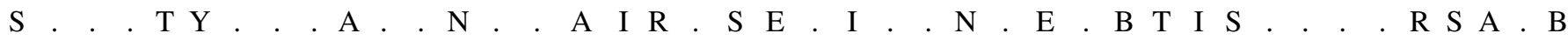
$\mathrm{I} . \cdot \mathrm{US}$. . $\mathrm{G} \cdot \mathrm{A} \cdot$.. $\mathrm{NO} \cdot \mathrm{S} \cdot \mathrm{G} \cdot \mathrm{G} \cdot \mathrm{N} \cdot \mathrm{O} \mathrm{I} \mathrm{Z} \mathrm{T} \cdot$. $\cdot \mathrm{C} \mathrm{I}$. I $\mathrm{B}$. . $\mathrm{R}$. . . $\mathrm{E}$. $\mathrm{L}$. . $\mathrm{GN}$. . . $\mathrm{H}$. . . $\mathrm{T}$. R C A R. . . E $\mathrm{N}_{\text {. }} \mathrm{L}$ $\mathrm{I}$. . . $\mathrm{E}$. . . . . . . . . . . I . . . . $\mathrm{T}$. . . . . . A $\mathrm{T} \mathrm{U}$. . . S G . I

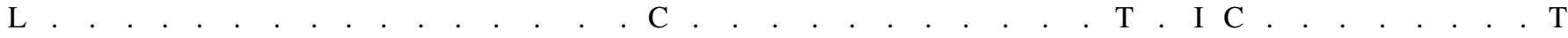

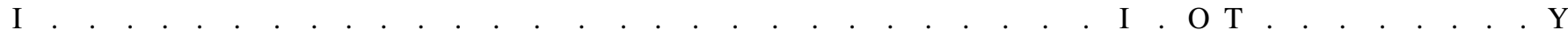

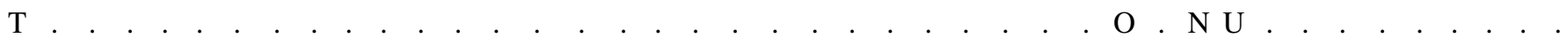
$\mathrm{Y}$

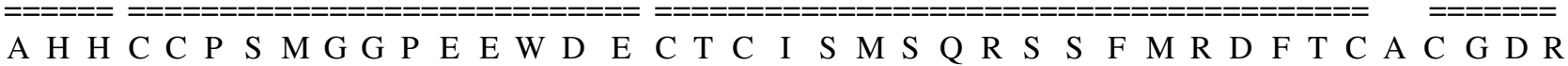
M I O O O E M U E L A M X E E C O E O N C E O U E E O O O E I O E O R O A I O E S M N U E A L N O T P P B M O D C M D I D C A L N U R B S A R S N T M M S L R T E T N R R T D B T I L S I O . E T. T I E A E R O I C O. N E M N C O I G E H M L S O I I E . . . A.

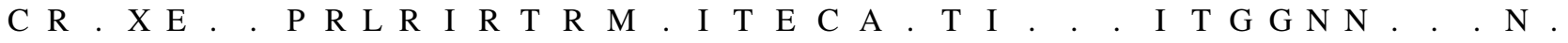

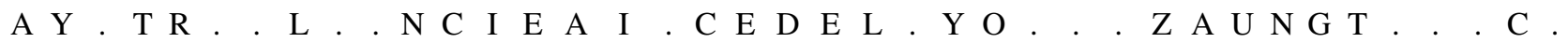
$\mathrm{N}$. . . . $\mathrm{E}$. $\mathrm{S} \mathrm{A} \mathrm{N} \mathrm{C} \mathrm{C}$. $\mathrm{A} \mathrm{N}$. . . $\mathrm{U}$. . $\mathrm{A} \mathrm{N}$. . . . . $\mathrm{E}$. .. . . . . . $\mathrm{L} G$ G $\mathrm{Y}$. $\mathrm{L} \mathrm{C} A$. . $\mathrm{S}$. . $\mathrm{T} \mathrm{C}$. . . . . . . . . . . . . . . . E. . . . . . . I E....... . . . 
TABLE 3

Most frequent words, and dendogram/semantic clusterings of 160 most frequent words, in paper titles from AoIR 2003 conference (clusters marked by horizontal bars) (Continued)

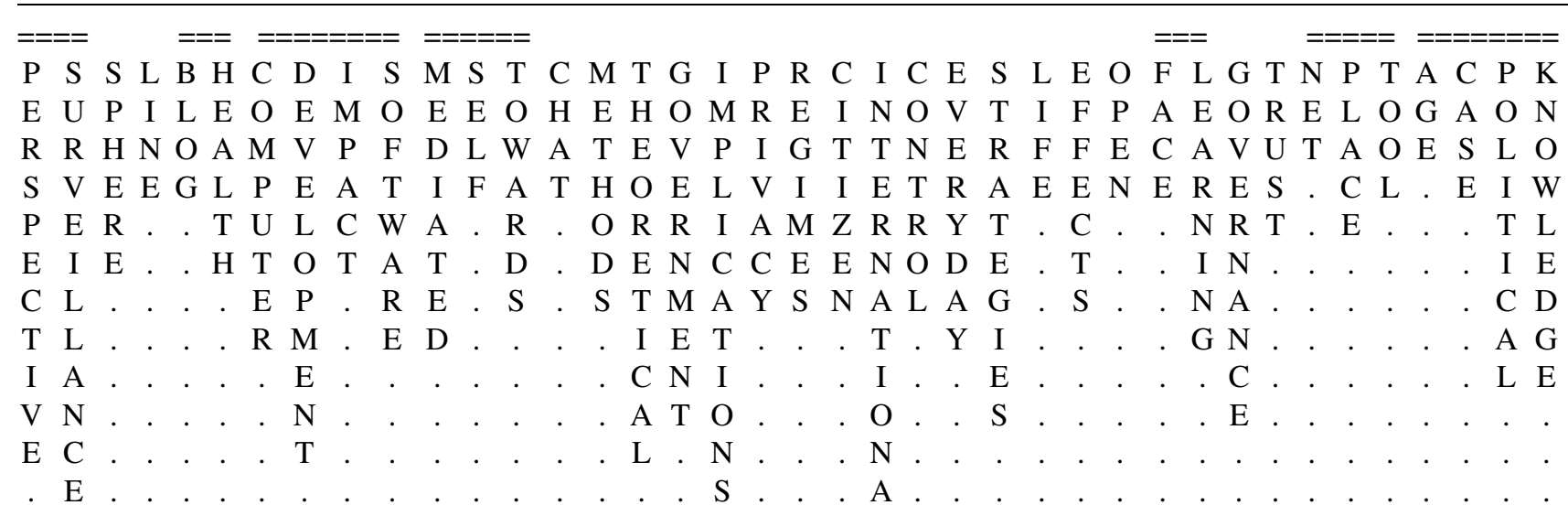

E S D C E C P W P U A P B

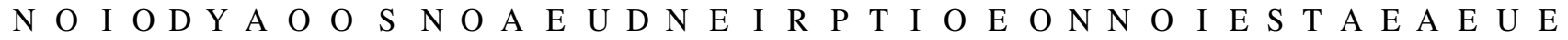
V C V N U B R R L E A L S W B E F C S A A U R M B M T L C G S S H N S T T L D

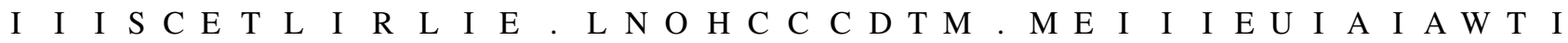
R E D T A R I D C S Y T D. I T R N O T E Y U U. U R N A T A E C G G. O U A O T E R T S C. Y . S I . C I M O U I. A N N N E L A R S E N R R .


$\mathrm{M}$.. $\mathrm{COAP} \mathrm{P}$. . . $\mathrm{S} \mathrm{S}$. . $\mathrm{Y} \mathrm{T} \mathrm{O} \mathrm{S}$. . $\mathrm{C}$. $\mathrm{T} \mathrm{T}$. . $\mathrm{H}$. $\mathrm{E}$. . .

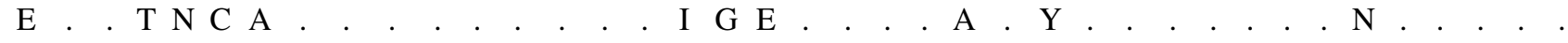

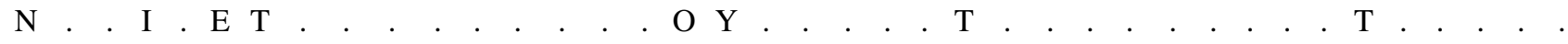

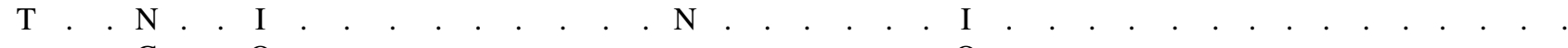

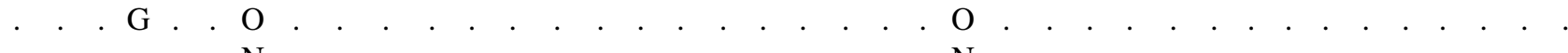

(g) web and media communication; and (h) a larger cluster consisting of social networks/community/culture, research/design, and online/digital/Internet. The broad issue of research/constructing online/network/Internet social/community is a cohesive and distinct AoIR theme. Participation/knowledge in politics/society/world and gaming/education/information/technology were the primary areas in a more wide-ranging grouping of themes.

\section{Paper Abstracts-2003}

Table 4 provides the most frequent words in the 2003 AOIR conference paper abstracts. The main conference themes from the sessions and paper titles are reinforced as well as elaborated through emphases on: (a) online, Internet, network; (b) research, study, analysis; (c) community, social; (d) technology, web, media; (e) digital divide, access; (f) communication, culture, public; (g) practice, user, design, experience, process; (h) work, organization; and (i) people, relationship, identity, society.
Because the large number of words from all the abstracts makes it difficult to portray all the clusters, and any cutoff either clusters a large number of words or does not include a large number, with the final clustering and scaling including only the most frequent words (those occurring 15 or more times). The primary semantic cluster from the content of the short abstracts includes (a) social analysis/research of online/Internet communication, community and information. At a slightly more general level, this primary cluster includes substantive issues of (b) access, individuals, groups, digital media, and culture. At the same general level appear two additional semantic clusters: (c) role and process in e-organizations, and world development. At the third level, a more general clustering includes (d) the web and (social) practices in the first cluster, combines the second and third cluster with (e) data, explore, and use and work experience, and adds (f) specific clusters of public/political sites, and knowledge design. The multidimensional scaling (not shown here) indicates a very clear distinction between the most general cluster of topics-research/analysis 
TABLE 4

Most frequent words, and dendogram/semantic clusterings of 160 most frequent words (those occurring 15 or more times), in paper abstracts from AoIR 2003 conference (clusters marked by horizontal bars)

Most frequent words (number and percent): Internet (322, 5.5\%), online (183, 3.1\%), community $(148,2.5 \%)$, social (139, $2.4 \%)$, study $(121,2.1 \%)$, technology $(114,1.9 \%)$, research $(104,1.8 \%)$

From 83 (1.4\%) to 91 times (1.6\%): information, new, communication, web, culture, media

From 60 (1\%) to 71 times (1.2\%): examine, based, network, result, public, digital, site

From $52(.9 \%)$ to 59 time (1\%): analysis, practice, user, political, group, issue, design, discuss

From 43 (.7\%) to 49 times (0.8\%): explore, individual, knowledge, data, development, different, e, work, process, access, experience, organization

From 30 (.5\%) to 39 times ( $0.7 \%$ ): world, role, environment, people, provide, argue, interaction, time, important, relationship, space, used, computer, content, context, form, identity, presentation, web site, virtual, mediated, model, society, system

From 20 (.3\%) to 29 times $(0.5 \%)$ : case, present, project, implication, member, participant, self, software, learning, uses, approach, education, part, particular, critical, government, health, over, related, researcher, strategy, discourse, divide, focus, future, question, chat, construction, game, ict, open, survey, technical, terms, concept, impact, participation, privacy, suggest, support, attention, behavior, current, language, understand

From 15 (.3\%) to 19 times (0.3\%): cyberspace, face, global, interview, local, means, number, offline, order, theory, traditional, com, economic, home, panel, recent, understanding, including, nature, place, possible, show, trust, control, countries, example, field, framework, human, key, life, literature, play, program, projects, theoretical, American, effects, empirical, national, net, non, notion, perspective, questions, set, specific, surveys, upon, various, weblogs

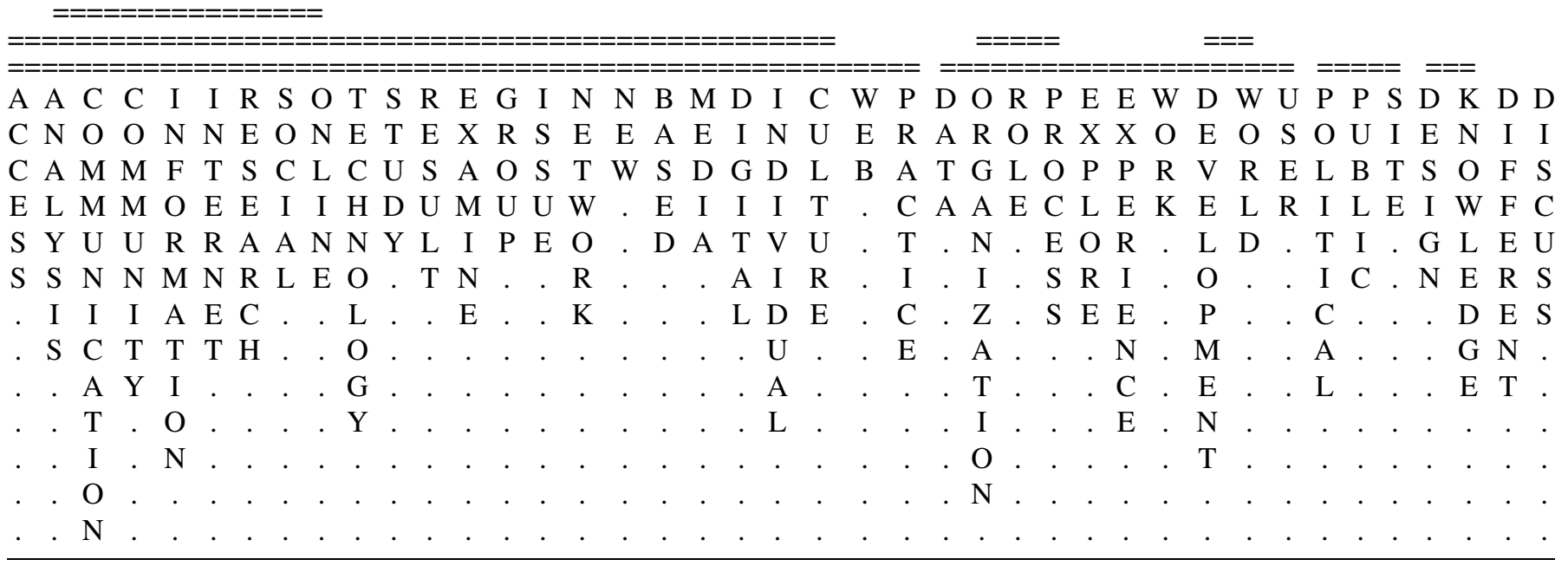

of online/Internet/technology communication/community at the individual and cultural level—and the remaining topics, ranging from public/political/user to development/process/design/knowledge.

\section{Session Titles-2004}

Compared to the 2003 session titles, the session titles from the 2004 AoIR conference were clearly worded by the organizers to be more succinct, shorter, and general, with several session titles used multiple times, differentiated by a number (such as Blogs, Journals, and Diaries, 1, 2, 3 , and 4). Table 5 lists the 56 most frequent words from these session titles.

Individual topics grouped together to identify more semantic session themes. Semantic clusters of the 56 most frequent words (occurring two or more times) in- cluded: (a) access to the Internet; (b) discourse and writing; (c) open source; (d) applications, searching, methodology, relationships, space, and education; (e) campaigns and politics; (f) policy; (g) social networks and community; (h) conceptualizing the Internet; (i) Internet news; (j) blogs; (k) inter(national) systems; and (l) online research.

\section{Paper Titles-2004}

The most frequent words appearing in the 2004 paper titles (Table 6) included topics such as: (a) Internet, online, web, network, computer, technology, wireless, interactivity, e-mail, ICT, web site; (b) community, social, network, support; (c) research, analysis, science, survey; (d) politics, democracy, elections, policy, power, participation, resistance; (e) self, identity, personal, presentation, voices; (f) culture, context, comparison, society; (g) national, 
TABLE 5

Most frequent words, and semantic clusterings of 56 most frequent words (occurring two or more times), in session titles from AoIR 2004 conference

Most frequent words (number and percent): online $(15,6.2)$, Internet $(6,2.8)$

5 times (2.1\% each): access, community, games, international, national, systems

4 times (1.7\% each): adoption, blogs, collaboration, diaries, digital, divide, journals, politics, social, ubiquity

3 times (1.2\% each): discourse, edemocracy, education, information, learning, metaphors, networks, space

[access digital divide adoption ubiquity]

[analysis of writing discourse wiki uses]

[open source collaboration]

[[applications (art, commerce, health, games), links \& searching, methodology and ethics, relationships and self] [space geographies] [education learning]]

[[electronic campaigns] [politics and edemocracy]]

[information and net governmental policy]

[social networks and community]

[concepts, metaphors, philosophies]

[traditional and Internet news, journalism, media]

[blogs, diaries, journals]

[national and international systems]

[online research]

Note. Hierarchical semantic clusters marked by brackets, at two cutoffs-more general [external brackets], and more specific [internal brackets].

USA, UK, Europe, world, global; (h) learning, education, faculty, university; (i) discourse; (j) gaming, play; (k) women, gender; (l) health; (m) space; (n) access and adoption. As the 2003 conference introduced blog research, the 2004 conference introduced wiki and sims research.

Clustering identified how those terms related semantically, but not as clearly as with the 2003 paper titles. Main clusters included: (a) community, communication and content; (b) culture, cyberspace, education, information, exploration, and gaming; (c) offline and online/Internet learning and interactivity; (d) research in sites of public practice and politics; (e) social and society, space and ubiquity; (f) analysis and context of personal (and possibly national) cyberidentity; (g) democracy and elections, health support; (h) policies and presentation relating to women. One possible explanation for the lack of as clearly meaningful semantic clusters may be that while there are many different words, they seem to be more evenly interrelated in 2004, implying a cross-diffusion of terms and concerns across specific research interests. In particular, the most common terms-Internet, online, community, web, ubiquity (the theme of the conference, after all!), social, infor- mation, and communication - seem to pervade the paper titles, making it more difficult to identify distinct semantic clusters. Figure 2 presents the multidimensional scaling of relationships among these 72 most frequent words, with Internet, design, digital, and online far to the right bottom outside the bounds of this space. Note that there are few distinct clusters within this inner large cluster of terms.

\section{Paper Abstracts-2004}

The 102 most frequent words in the abstracts reflect the most frequent words in the paper titles (see Table 7): Internet and online, social, community, information, research, user, web, communication, network, culture, political, space, gaming, practice, system, society, self, relationship, identity, learning, women, news, policy, blogs, discourse, gender, power, education, government, health, participation, ubiquity. A few additional specific words appeared: group, people, time, theory, life, knowledge, interviews, local, global, structure, players, human, sense. Other frequent words appearing in the abstracts tended to be of a more general or adjectival nature, such as question, form, project, important, part, related, approach, activities, various, etc.

The primary semantic clusters emerging from the relationships among the most frequent words in the abstracts included: (a) accessing others and activities; (b) news and social issues through online technology; (c) researching the role of the individual in communities; (d) Internet, networks, and information; (e) user-based studies; (f) questions about communication, culture, and work; (g) use data and time; (h) forms of people and groups; (i) life and becoming; (j) practice; (k) potential sites; (l) media, web, society, and the world; (m) public relationships; (n) digital games; (o) traditional content; (p) blogs, women, and search policy; (q) students learning through local web sites; (r) global and country-specific members and participants; (s) surveys; (t) contexts; (u) e-mail interviews; (v) knowledge and support; (w) experience and process; (x) self and identity; (y) computer system; (z) placing orders; and (aa) virtual space.

\section{LIMITATIONS}

Clearly, even a population of texts from two conferences of a major interdisciplinary association for Internet researchers can in no way be generalized to the research agenda of everyone conducting research on social aspects of the Internet. There is likely no way to do a completely "representative" analysis of what people are studying; given the interdisciplinary nature of Internet research, it would be probably impossible to even identify all the possible sources. However, it's not unreasonable to argue that papers evaluated and accepted for the primary conference 
TABLE 6

Most frequent words, and dendogram/semantic clusterings of 72 most frequent words (those occurring five or more times), in paper titles from AoIR 2004 conference (clusters marked by horizontal bars)

Most frequent words (number and percent): Internet $(105,12.9)$, online (77, 9.5\%)

From 21 (2.6\%) to 26 (3.2\%): community, web, ubiquity, social, information

From 10 (1.2\%) to 15 times (1.8\%): digital, network, communication, politics, practice, research, study, virtual, site, cultural, game, context, self, comparison, computer, USA

From 8 (1\% to 9 (1.1\%): access, user, world, case, Europe, group, identity, technology, UK

7 times (0.9\%): analysis, based, cyber, emerging, exploration, learning, life, media, perspective, public, support

6 times $(0.7 \%)$ : age, democracy, education, ethics, gender, Korea, offline, personal, policy, search, society, women

5 times (0.6\%): American, content, cyberspace, development, discourse, elections, global, health, interactivity, mobile, power, presentation, race, role, science, space, wireless

4 times (0.4\%): adoption, approach, children, ebay, economy, electronic, e-mail, everyday, faculty, ict, line, mediated, national, participation, resistance, small, structure, surveillance, survey, time, university, voices, web site

3 times (0.3\%): action, Asian, assessment, audience, broadband, campaigning, challenges, citizens, club, code, construction, design, differences, different, disciplinary, divide, domestic, ecommerce, engines, environments, ethnography, evaluating, expectations, factors, fan, framing, gay, go, home, importance, interaction, international, livejournal, mapping, mass, men, multiple, net, people, play, post, presence, privacy, project, realities, researching, sense, strategies, systems, technologies, uses, value, young



C D D L M N S T U W W D E G G M P A C C E I P P D E H S E P P W

$\begin{array}{llllllllllllllllllllllllllllllll}O & E & I & I & O & E & E & E & S & I & O & I & M & L & R & E & E & N & O & Y & U & D & E & O & E & L & E & U & T & O & R & O\end{array}$

M V V S

$\begin{array}{llllllllllllllllllllllllllllllll}P & E & C & E & I & W & F & H & R & E & L & I & R & B & U & I & S & L & T & E & O & N & S & E & O & C & L & P & I & I & S & E\end{array}$

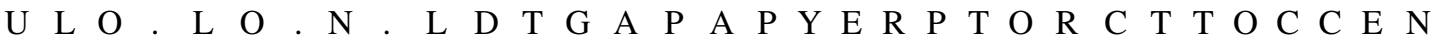

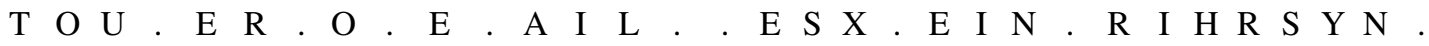

$\mathrm{E} P \mathrm{R} \cdot \mathrm{K} \cdot \mathrm{L} \cdot \mathrm{S} \cdot \mathrm{L}$. . $\mathrm{C} \mathrm{I}$. $\frac{\mathrm{T} A}{\mathrm{~A}} \mathrm{~A} \mathrm{O} \cdot \mathrm{T} \cdot \mathrm{T}$.

$\mathrm{R} \mathrm{S}$. . . $\mathrm{O} . \mathrm{S} . \mathrm{G} . . \mathrm{T}$. . . $\mathrm{Y} \mathrm{L} . \mathrm{C}$. . . $\mathrm{A}$.

E E. . . G. . . . . . . . . . . $\mathrm{Y}$. . . . $\mathrm{T}$.

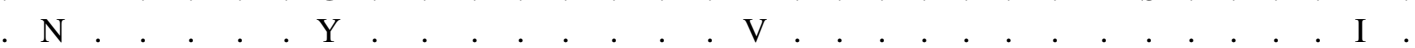

. $\mathrm{T}$. . . . . . . . . . E. . . . . . . . . $\mathrm{O}$.

. . . . . . . . . . . . . . . . . . . . . . . . . . $\mathrm{N}$.

on socially oriented Internet research are reasonable indicators.

This study considered research topics from two AoIR conferences at four levels: conference themes, session titles, paper titles, and paper abstracts. It might be suggested that each conference's main theme is a simple statement of the research agenda of that conference's presenters. There are many arguments against this, however. First, such themes are determined usually by one or a few people a year or so before the conference, not based on what 


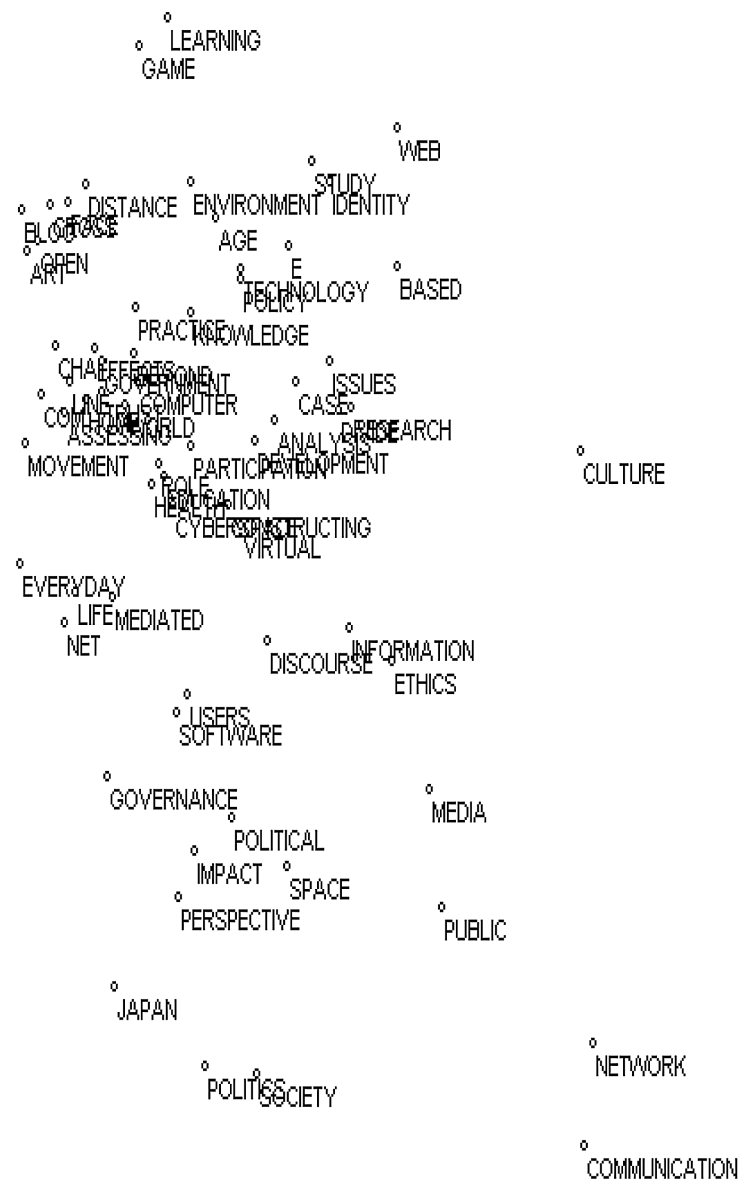

COMMUNITY

SOCIAL

FIG. 2. Two-dimensional scaling of 72 most frequent words from 2004 conference paper titles.

is actually submitted, accepted, or presented. Second, the themes are quite succinct, and cannot possibly provide the range of topics included in even the session titles, much less the paper titles or abstracts. Further, few authors explicitly craft even their paper title to align with a conference theme. Because of submission deadlines, most researchers already have a study or paper in progress by the conference announcement. Finally, in fact the 2003 theme was not much reflected in the titles or abstracts, while the 2004 theme of "ubiquity" and words from the statement, such as community, context, and politics, did appear. But, except for "ubiquity," those terms also appeared in the 2003 texts, and, of course, many other words and concepts appeared.

Of course, not all paper titles or all abstracts perfectly convey the primary theme or focus of the paper; nor would it always be a simple matter to identify just what that theme is. Some concepts in the 2003 abstracts are in un- known ways possibly over- or underemphasized through the organizers' shortening of some of them to a generally similar length, especially for the French papers and papers that originally had much longer abstracts, though that approach does equally weight each abstract in the analysis. Alternatively, those 2004 abstracts that are noticeably longer than others may overemphasize certain concepts in the overall data set. Also, the organizers took different approaches to labeling the session titles for the 2003 and the 2004 conferences. However, considerable prior research has used and justified the analytical approach used here, and the full population of AoIR papers would seem sufficiently large to wash out idiosyncrasies of individual word choices. Further, there seems to be good correspondence between the main topics of the paper titles and their abstracts, indicating some reliability of the different sources. Given the origin of the text (conference organizers, or authors), and the results provided here (with little new added 
TABLE 7

Most frequent words, and dendogram/semantic clusterings of 102 most frequent words (those occurring 105 or more times), in paper abstracts from AoIR 2004 conference (clusters marked by horizontal bars)

Most frequent words (1.7\%): Internet (1874, 6.3\%), online (822, 2.7\%), social $(763,2.6 \%)$, community $(656,2.2 \%)$, information $(579,1.9 \%)$, technology $(552,1.8 \%)$, research $(550,1.8 \%)$, user $(530,1.8 \%)$, web $(513,1.7 \%)$, paper $(500,1.7 \%)$

From 289 (1.0\%) to 431 (1.4\%): site, communication, study, group, network, cultural, media, individual, political, analysis, people, based, different, space

From 196 (.7\%) to 277 (.9\%): game, question, time, data, access, understand, practice, form, virtual, world, used, studies, work, system, two, society, public, theory, self, computer, life

From 105 (.4\%) to 1878 (.6\%): relationship, first, survey, digital, project, identity, personal, development, content, important, learning, context, part, role, students, web site, knowledge, ways, potential, e-mail, issues, provide, members, number, results, specific, participants, interviews, order, search, USA, interaction, place, others, become, focus, support, traditional, process, example, experience, women, particular, countries, local, related, might, approach, news, policy, blogs, uses, activities, level, everyday, various, global

From 79 (.3\%) to 104 (.3\%): terms, case, discourse, structure, tools, discussion, second, findings, current, offline, factors, players, found, gender, line, researchers, aspects, general, nature, power, significant, home, several, education, examine, chat, design, means, technological, three, medium, model, services, themselves, years, economic, government, environment, impact, differences, health, changes, lives, academic, complex, interest, participation, physical, real, set, ubiquitous, help, need, human, implications, presentation, range, sense

\begin{tabular}{|c|c|c|c|c|c|c|c|c|c|c|c|c|c|c|c|c|c|c|c|c|c|c|c|c|c|c|c|c|c|c|c|c|c|c|c|c|c|}
\hline \multicolumn{8}{|c|}{ 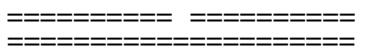 } & \multicolumn{8}{|c|}{ 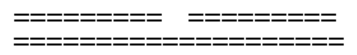 } & \multicolumn{8}{|c|}{ 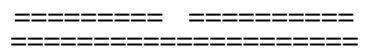 } & \multicolumn{7}{|c|}{  } & \multicolumn{6}{|c|}{ 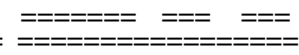 } & \\
\hline A & $\mathrm{P}$ & A & & $\mathrm{N}$ & $\mathrm{S}$ & $\mathrm{O}$ & $\mathrm{T}$ & $\mathrm{C}$ & I & $\mathrm{R}$ & $\mathrm{R}$ & I & $\mathrm{N}$ & I & $\mathrm{P}$ & A & $\mathrm{S}$ & B & $\mathrm{U}$ & $\mathrm{C}$ & Q & $\mathrm{C}$ & W & $\mathrm{D} T$ & $D$ & $\mathrm{U}$ & $\mathrm{F}$ & $\mathrm{F}$ & $\mathrm{G}$ & $\mathrm{P}$ & B L & L W & W $\mathrm{F}$ & $\mathrm{P} \quad \mathrm{P}$ & $\mathrm{P}$ & $\mathrm{S}$ & \\
\hline $\mathrm{C}$ & A & $\mathrm{C}$ & $\mathrm{T}$ & E & $\mathrm{O}$ & $\mathrm{N}$ & E & $\mathrm{O}$ & $\mathrm{N}$ & E & $\mathrm{O}$ & $\mathrm{N}$ & $\mathrm{E}$ & $\mathrm{N}$ & A & $\mathrm{N}$ & $\mathrm{T}$ & A & S & $\mathrm{O}$ & U & $\mathrm{U}$ & $\mathrm{O}$ & A I & I & $\mathrm{S}$ & I & $\mathrm{O}$ & $\mathrm{R}$ & E & E I & I A & A A & $A \quad R$ & $\mathrm{O}$ & I & \\
\hline $\mathrm{C}$ & $\mathrm{R}$ & $\mathrm{T}$ & $\mathrm{H}$ & W & $\mathrm{C}$ & $\mathrm{L}$ & $\mathrm{C}$ & M & $\mathrm{D}$ & $\mathrm{S}$ & $\mathrm{L}$ & $\mathrm{F}$ & $\mathrm{T}$ & $\mathrm{T}$ & $\mathrm{P}$ & A & $\mathrm{U}$ & $S$ & $\mathrm{E}$ & M & E & $\mathrm{L}$ & $\mathrm{R}$ & $\mathrm{T} \mathrm{M}$ & $1 \mathrm{~F}$ & $\mathrm{E}$ & $\mathrm{R}$ & $\mathrm{R}$ & $\mathrm{O}$ & $\mathrm{O}$ & C F & F Y & $\mathrm{Y} \quad \mathrm{R}$ & $\mathrm{R} \quad \mathrm{A}$ & $\mathrm{T}$ & $\mathrm{T}$ & \\
\hline $\mathrm{E}$ & $\mathrm{T}$ & I & E & $S$ & I & I & $\mathrm{H}$ & M & I & $\mathrm{E}$ & $\mathrm{E}$ & $\mathrm{O}$ & W & $\mathrm{E}$ & $\mathrm{E}$ & L & D & $\mathrm{E}$ & $\mathrm{R}$ & M & $S$ & $\mathrm{~T}$ & $\mathrm{~K}$ & A E & $\mathrm{F}$ & $\mathrm{D}$ & $\mathrm{S}$ & $\mathrm{M}$ & $\mathrm{U}$ & $\mathrm{P}$ & $\mathrm{O} E$ & E S & $S$ & T C & $\mathrm{E}$ & $\mathrm{E}$ & \\
\hline $\mathrm{S}$ & I & $\mathrm{V}$ & $\mathrm{R}$ & . & A & $\mathrm{N}$ & $\mathrm{N}$ & $\mathrm{U}$ & $\mathrm{V}$ & A & . & $\mathrm{R}$ & $\mathrm{O}$ & $\mathrm{R}$ & $\mathrm{R}$ & $\mathrm{Y}$ & $\mathrm{Y}$ & D & & $\mathrm{U}$ & $\mathrm{T}$ & $\mathrm{U}$ & & . & E & r & $\mathrm{T}$ & . & $\mathrm{P}$ & $\mathrm{L}$ & M & & & . $\mathrm{T}$ & $\mathrm{N}$ & . & \\
\hline S & $\mathrm{C}$ & I & $S$ & . & $\mathrm{L}$ & $\mathrm{E}$ & $\mathrm{O}$ & $\mathrm{N}$ & I & $\mathrm{R}$ & . & $\mathrm{M}$ & $\mathrm{R}$ & $\mathrm{N}$ & . & S & 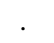 & & . & $\mathrm{N}$ & I I & $\mathrm{R}$ & & . & $\mathrm{R}$ & 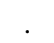 & . & r & . & $\mathrm{E}$ & $\mathrm{E}$ & & & . I & $\mathrm{T}$ & . & \\
\hline & $\mathrm{U}$ & $\mathrm{T}$ & . & . & . & . & $\mathrm{L}$ & I & $\mathrm{D}$ & $\mathrm{C}$ & & A & $\mathrm{K}$ & $\mathrm{E}$ & & I & . & & . & I & $\mathrm{O}$ & A & $\theta^{\circ}$ & . & $\mathrm{E}$ & . & . & 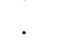 & . & 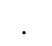 & . & . & . & . $\mathrm{C}$ & I & . & \\
\hline & $\mathrm{L}$ & I & . & . & . & . & $\mathrm{O}$ & $\mathrm{T}$ & $\mathrm{U}$ & $\mathrm{H}$ & & $\mathrm{T}$ & & $\mathrm{T}$ & . & S & ? & & . & $\mathrm{C}$ & $\mathrm{N} \mathrm{I}$ & $\mathrm{L}$ & . & . & $\mathrm{N}$ & . & . & 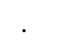 & . & . & 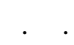 & 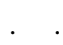 & . & . $\mathrm{E}$ & A & ${ }^{\circ}$ & \\
\hline & A & $\mathrm{E}$ & . & . & . & . & $\mathrm{G}$ & $\mathrm{Y}$ & A & . & . & I & . & . & . & & . & 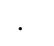 & . & A & . & . & . & . & $\mathrm{T}$ & . & . & . & . & & . & . & . &.$\quad$. & $\mathrm{L}$ & & \\
\hline & $\mathrm{R}$ & $\mathrm{S}$ & . & . & . & . & $\mathrm{Y}$ & . & $\mathrm{L}$ & . & . & $\mathrm{O}$ & 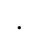 & . & . & . & . & . & . & $\mathrm{T}$ & . & . & . & . & . & . & . & . & . & . & . & . & . &.$\quad$. & . & 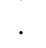 & \\
\hline & . & . & $\cdot$ & . & . & . & $\cdot$ & . & . & . & . & $\mathrm{N}$ & . & . & . & . & . & . & 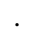 & I & . & . & . & . & . & . & . & . & . & . & . . & . & . &.$\quad$. & . & . & \\
\hline & . & . & $\cdot$ & . & . & . &. & . & . & . & . & . & 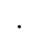 & . & . & . & . & & . & $\mathrm{O}$ & . & . & . & . & . & . & . & . & . & . & . . & . & . &.$\quad$. & . & . & \\
\hline & . & . & . & . & . & . &. & . & . & . & 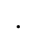 & . & 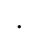 & . & . & . & . & $\cdot$ & . & $\mathrm{N}$ & . & . & . & . & . & . & . & . & . & . & . . & & . & $\cdot$. & . & . & \\
\hline$=$ & $===$ & $===$ & $===$ & $===$ & $===$ & $==$ & $===$ & & & & & $==$ & $==$ & $===$ & $==$ & $==$ & $===$ & $===$ & $==$ & & $===$ & $===$ & $===$ & & $:==$ & & $==$ & $===$ & $==$ & & $====$ & & $====$ & & $==$ & & \\
\hline & $===$ & $=$ & & & -- & & & & $==$ & $==$ & & . & $==$ & $===$ & & $=$ & $===$ & $=$ & $=$ & & & $=$ & $==$ & & & & & & & & $=====$ & & & $===$ & & & \\
\hline I & $\mathrm{T}$ & S & $\mathrm{U}$ & M & W & $\mathrm{S}$ & W & $\mathrm{P}$ & $\mathrm{P}$ & $\mathrm{R}$ & $\mathrm{T}$ & A & $\mathrm{I}$ & $\mathrm{D}$ & $\mathrm{U}$ & $\mathrm{G}$ & $\mathrm{L}$ & $\mathrm{C}$ & $\mathrm{T}$ & $\mathrm{N}$ & B V & W & $\mathrm{P}$ & $\mathrm{S} \quad \mathrm{L}$ & $S$ & $\mathrm{~L}$ & W & $\mathrm{C}$ & $\mathrm{G}$ & $\mathrm{R}$ & $\mathrm{M} \mathrm{P}$ & $\mathrm{P} \quad \mathrm{E}$ & E M & $M \mathrm{~F}$ & $\mathrm{U}$ & $\mathrm{P}$ & $\mathrm{R}$ \\
\hline M & W & $\mathrm{T}$ & $\mathrm{N}$ & E & E & $\mathrm{O}$ & $\mathrm{O}$ & $\mathrm{R}$ & $\mathrm{U}$ & E & $\mathrm{H}$ & $\mathrm{P}$ & $\mathrm{N}$ & I & $\mathrm{S}$ & A & E & $\mathrm{O}$ & $\mathrm{R}$ & L & L & $\mathrm{O}$ & $\mathrm{O}$ & E E & $\mathrm{T}$ & $\mathrm{O}$ & E & $\mathrm{O}$ & $\mathrm{L}$ & E & & A $V$ & V I & I $\mathrm{O}$ & $\mathrm{S}$ & E & E \\
\hline $\mathrm{P}$ & $\mathrm{O}$ & $\mathrm{U}$ & D & $\mathrm{D}$ & B & $\mathrm{C}$ & $\mathrm{R}$ & $\mathrm{O}$ & B & $\mathrm{L}$ & $\mathrm{E}$ & $\mathrm{P}$ & $\mathrm{T}$ & G & $\mathrm{E}$ & $\mathrm{M}$ & $\mathrm{V}$ & $\mathrm{N}$ & A & M & $\mathrm{ON}$ & M & $\mathrm{L}$ & A A & $\mathrm{U}$ & $\mathrm{C}$ & B & $\mathrm{U}$ & $\mathrm{O}$ & $\mathrm{S}$ & $\mathrm{M} \mathrm{R}$ & $\mathrm{R} \quad \mathrm{E}$ & E G & $\mathrm{G} C$ & A & $\mathrm{R}$ & $\mathrm{L}$ \\
\hline $\mathrm{O}$ & . & $\mathrm{D}$ & E & I & . & I & $\mathrm{L}$ & V & $\mathrm{L}$ & A & $\mathrm{O}$ & $\mathrm{R}$ & $\mathrm{E}$ & I & S & $\mathrm{E}$ & $\mathrm{E}$ & $\mathrm{T}$ & $\mathrm{D}$ & E & G & E & I & $\mathrm{R} R$ & $\mathrm{D}$ & A & $\mathrm{S}$ & $\mathrm{N}$ & B & $\mathrm{U}$ & B $\mathrm{T}$ & $\mathrm{T} \quad \mathrm{R}$ & $\mathrm{R} \quad \mathrm{H}$ & $\mathrm{HU}$ & & S & A \\
\hline $\mathrm{R}$ & & I & $\mathrm{R}$ & A & 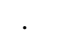 & $\mathrm{E}$ & $\mathrm{D}$ & I & I & $\mathrm{T}$ & $\mathrm{R}$ & $\mathrm{O}$ & $\mathrm{R}$ & $\mathrm{T}$ & & & $\mathrm{L}$ & $\mathrm{E}$ & I & E & S I & $\mathrm{N}$ & $\mathrm{C}$ & $\mathrm{C} N$ & E & $\mathrm{L}$ & I & $\mathrm{T}$ & A & $\mathrm{L}$ & E I & I $\quad Y$ & $\begin{array}{ll}Y & T\end{array}$ & T $\mathrm{S}$ & & $\mathrm{O}$ & \\
\hline $\mathrm{T}$ & . & E & $S$ & . & . & $\mathrm{T}$ & & $\mathrm{D}$ & $\mathrm{C}$ & I & $\mathrm{Y}$ & A & A & A & $\cdot$ & . & 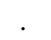 & $\mathrm{N}$ & $\mathrm{T}$ & $\mathrm{R}$ & . & . & $\mathrm{Y}$ & $\mathrm{H} \mathrm{I}$ & $\mathrm{N}$ & . & $\mathrm{T}$ & $\mathrm{R}$ & $\mathrm{L}$ & $\mathrm{T}$ & $\mathrm{R} C$ & C D & $\mathrm{D}$. & . & . & $\mathrm{N}$ & E \\
\hline A & 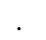 & $\mathrm{S}$ & $\mathrm{T}$ & . & . & $\mathrm{Y}$ & & E & . & $\mathrm{O}$ & . & $\mathrm{C}$ & $\mathrm{C}$ & $\mathrm{L}$ & r & r. & . & $\mathrm{T}$ & I & & . & . & . & . $\mathrm{N}$ & $T$ & . & E & I & . & $\mathrm{S}$ & S I & I A & A. & . & . & A & D \\
\hline $\mathrm{N}$ & . & . & A & . & . & . & $\cdot$ & . & . & $\mathrm{N}$ & & $\mathrm{H}$ & $\mathrm{T}$ & 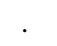 & r & . & . & & $\mathrm{O}$ & &  & ${ }^{\circ}$ & . & . $\mathrm{G}$ & $S$ & $\cdot$ & . & $\mathrm{E}$ & $\cdot$ & . & . $\mathrm{P}$ & $\mathrm{P} \quad \mathrm{Y}$ & $\mathrm{Y}$ & 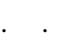 & . & $\mathrm{L}$ & \\
\hline $\mathrm{T}$ & . & . & $\mathrm{N}$ & . & . & . & . & . & . & $\mathrm{S}$ & $\cdot$ & . & I & $\cdot$ & . & . & . & & $\mathrm{N}$ & & . & . & . & . & . & . & . & $\mathrm{S}$ & . & . & & A & & . & . & . & \\
\hline & . & . & $\mathrm{D}$ & . & . & . & · & . & & $\mathrm{H}$ &  & 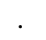 & $\mathrm{O}$ & 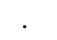 & . & . & . & & A & & . & . & . & . & . & . & . & . & . & . & . $\mathrm{N}$ & $\mathrm{N}$ & & . & & r & \\
\hline & . & . & . & . & . & . & . & . & . & I & . & 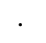 & $\mathrm{N}$ & . & . & . & . & . & $\mathrm{L}$ & 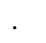 & . & . & . & . & . & . & . & . & . & . & & $\mathrm{T}$ & & . & . & . & \\
\hline & . & . & . & . & . & . & & . & . & $\mathrm{P}$ & . & . & . & 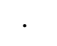 & . & . & . & . & . & 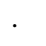 & . & . & . & 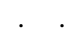 & . & . & . & . & . & 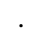 & . $\mathrm{S}$ & $S$ & & . & . & . & \\
\hline & & & & & $===$ & & & & & $=$ & & & & & & $=$ & & & & & & & & & & & & & & & & & & & & & \\
\hline$==$ & & $==$ & $==$ & $===$ & $===$ & $==$ & & $===$ & & $==$ & & $==$ & $==$ & & & $==$ & & $==$ & & & & & & & & & & & & & & & & & & & \\
\hline $\mathrm{C}$ & $\mathrm{V}$ & E & I & K & $\mathrm{S}$ & $\mathrm{P}$ & S & E & $\mathrm{P}$ & I & S & $\mathrm{C}$ & $\mathrm{S}$ & $\mathrm{D}$ & E & $\mathrm{O}$ & $\mathrm{P}$ & $\mathrm{S}$ & V & & & & & & & & & & & & & & & & & & \\
\hline $\mathrm{O}$ & A & $\mathrm{M}$ & $\mathrm{N}$ & $\mathrm{N}$ & $\mathrm{U}$ & $\mathrm{R}$ & $\mathrm{P}$ & X & $\mathrm{R}$ & $\mathrm{D}$ & E & $\mathrm{O}$ & $\mathrm{Y}$ & $\mathrm{E}$ & $X$ & I & $\mathrm{L}$ & $\mathrm{P}$ & I & & & & & & & & & & & & & & & & & & \\
\hline$N$ & $\mathrm{R}$ & A & $\mathrm{T}$ & $\mathrm{O}$ & $\mathrm{P}$ & $\mathrm{O}$ & E & $\mathrm{P}$ & $\mathrm{O}$ & $\mathrm{E}$ & $\mathrm{L}$ & M & $S$ & V & A & I & A & & $\mathrm{R}$ & & & & & & & & & & & & & & & & & & \\
\hline $\mathrm{T}$ & I & I & E & W & $\mathrm{P}$ & $\mathrm{J}$ & $\mathrm{C}$ & $\mathrm{E}$ & $\mathrm{C}$ & $\mathrm{N}$ & $\mathrm{F}$ & $\mathrm{P}$ & $\mathrm{T}$ & $\mathrm{E}$ & M & $\mathrm{E}$ & $c$ & & 1 & 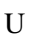 & & & & & & & & & & & & & & & & & \\
\hline E & $\mathrm{O}$ & $\mathrm{L}$ & $\mathrm{R}$ & $\mathrm{L}$ & $\mathrm{O}$ & $\mathrm{E}$ & I & $\mathrm{R}$ & E & $\mathrm{T}$ & & $\mathrm{U}$ & E & $\mathrm{L}$ & $\mathrm{P}$ & $\mathrm{K}$ & E & & U & & $\mathrm{T}$ & & & & & & & & & & & & & & & & \\
\hline$X$ & $\mathrm{U}$ & . & V & E & $\mathrm{R}$ & $\mathrm{C}$ & $\mathrm{F}$ & I & $\mathrm{S}$ & I & & $\mathrm{T}$ & $\mathrm{M}$ & $\mathrm{O}$ & 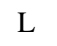 & & . & & A & $\mathrm{S}$ & 1 & & & & & & & & & & & & & & & & \\
\hline $\mathrm{T}$ & $\mathrm{S}$ & . & I & $\mathrm{D}$ & $\mathrm{T}$ & $\mathrm{T}$ & I & E & $\mathrm{S}$ & $\mathrm{T}$ & & E & & $\mathrm{P}$ & E & & . & & $\mathrm{L}$ & & $\mathrm{C}$ & & & & & & & & & & & & & & & & \\
\hline & . & $\cdot$ & $\mathrm{E}$ & G & . & . & $\mathrm{C}$ & $\mathrm{N}$ & . & $\mathrm{Y}$ & & $\mathrm{R}$ & & $\mathrm{M}$ & & & 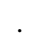 & & & & A & & & & & & & & & & & & & & & & \\
\hline & . & . & W & E & . & . & 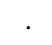 & C & . & . & · & . & & E & · & & . & & & & $\mathrm{L}$ & & & & & & & & & & & & & & & & \\
\hline & . & . & $\mathrm{S}$ & . & . & . & . & E & . & . & $\cdot$ & . & & $\mathrm{N}$ & & . & . & & & & . & & & & & & & & & & & & & & & & \\
\hline & 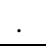 & . & 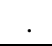 & 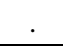 & 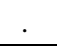 & 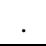 & & 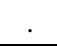 & 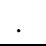 & 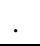 & & & & $\mathrm{T}$ & & & & & & & & & & & & & & & & & & & & & & & \\
\hline
\end{tabular}


from analysis of the abstracts), it seems that paper titles (given enough of them to constitute the range of topics; and published articles could provide a more highly filtered sample) provide the best basis for identifying the agenda of a particular sample of researchers.

There are many words that appear only once or twice, and they do reflect some unique perspectives, but the method used here generally ignores them. The main point of this kind of research is to identify general trends or distribution means. Unique words can always be found from the online AoIR programs.

Finally, deciding on the appropriate dendogram cutoffs, and thus the resulting semantic clusters, is somewhat subjective. However, cutoffs were chosen to highlight major differences, so that nearby choices would provide essentially the same results. Because of the nature of hierarchical clustering, however, considerably different cutoffs are always subsets of more general clusters, as presented in several of the tables. And while the semantic network approach does identify frequent words and related clusters, more formal approaches, such as a priori content analysis, close interpretations of selected abstracts, or cocitation analyses, could reveal more theoretically derived categories, more nuanced narratives, or more persistent relations among papers. However, as noted earlier, for large sets of text, this approach seems quite useful, though it might be complemented by such other approaches.

\section{DISCUSSION}

The clusterings of the most frequent words in the paper titles and abstracts seem to indicate two major dimensions of AoIR themes. On one dimension is the traditional continuum from social science research (here, specifically on online/Internet/technology, in information/communication and community realms) to specific applied sites, and on the other dimension is a continuum from specific usage and content realms, to more general and abstract processes and concepts. Certainly the major dimension of research (whether social science or cultural analysis) on Internet/online networks represents the primary identity of AOIR. And the second, less differentiated, dimension of practice, content, and sites, from the more applied to the more conceptual, represents one of the primary missions of AoIR-a "spirit of inclusiveness, curiosity, interdisciplinarity, and openness."

The research agenda of the papers presented at these two AoIR conferences thus seems both more focused (emphasizing Internet/online networks) as well as more general (emphasizing interdisciplinarity and broad realms of practice and concepts) than the area of new media research in one division of the International Communication, as summarized by Lievrouw et al. (2001). But it also reflects the new research directions suggested by Lievrouw et al.: con- texts and applications of Internet searching and communication, globalization, equity and political implications, popular culture and use of technologies at home and community, and mediated education.

The conceptual clusters identified from the paper titles and abstracts could be used to guide authors of literature/research reviews. Certainly such reviews would want to be sure to include most of these main topics, as they are the predominate interests of this group of Internet researchers. Internet research courses or even textbooks could benefit from covering the primary concept clusters, with individual assignments or discussions of the less frequent topics. Alternatively, areas that are not represented by these clusters might be topics for new research projects, and for considerations by review chapters of how new contexts might be related to these studied contexts.

The research agenda represented by the words and concept clusters in the session titles and paper titles and abstracts at these two conferences of the Association of Internet Researchers reflect and elaborate the growing trends in coverage of and research on the Internet.

\section{REFERENCES}

Callon, M., Courtial, J.-P., Turner, W., and Bauin, S. 1983. From translations to problematic networks: An introduction to co-word analysis. Social Science Information 2:191-235.

Carley, K., and Palmquist, M. 1992. Extracting, representing and analyzing mental models. Social Forces 70:601-636.

Chang, T. M. 1986. Semantic memory: Facts and Models. Psychological Bulletin 99:199-220.

Collins, A. M., and Quillian, M. R. 1969. Retrieval time from semantic memory. Journal of Verbal Learning and Verbal Behavior 8:240247.

Consalvo, M., Baym, N., Hunsinger, J., Jensen, K. B., Logie, J., Murero, M., and Shade, L. R., eds. 2004. Internet research annual, vol. 1: Selected papers from the Association of Internet Researchers conferences 2000-2002. New York: Peter Lang.

Danowski, J. 1982. A network-based content analysis methodology for computer-mediated communication: An illustration with a computer bulletin board. In Communication yearbook, vol. 6, ed. R. Bostrom, pp. 904-925. New Brunswick, NJ: Transaction Books.

Danowski, J. 1988. Organizational infographics and automated auditing: Using computers to unobtrusively gather and analyze communication. In Handbook of organizational communication, eds. G. Goldhaber and G. Barnett, pp. 385-434. Norwood, NJ: Ablex.

Danowski, J. A., and Martin, T. H. 1979. Evaluating the health of information science: Research community and user contexts. Contract IST78-21130. Washington, DC: National Science Foundation.

Doerfel, M. L., and Barnett, G. 1999. A semantic network analysis of the International Communication Association. Human Communication Research 25(4):589-603.

Doerfel, M. L., and Marsh, P. S. 2003. Candidate-issue positioning in the context of Presidential debates. Journal of Applied Communication Research 31:212-237. 
Flores-d'Arcais, G. B., and Schreuder, R. 1987. Semantic activation during object naming. Psychological Research 49:153159.

Jones, S. 2004. Imagining an association. In Internet research annual, vol. 1: Selected papers from the Association of Internet Researchers conferences 2000-2002, eds. M. Consalvo, N. Baym, J. Hunsinger, K. B. Jensen, J. Logie, M. Murero, and L. R. Shade, pp. 5-12. New York: Peter Lang.

Kim, S., and Weaver, D. 2002. Communication research about the Internet: A thematic meta-analysis. New Media \& Society 4(4):518538.

Lievrouw, L., Bucy, E., Finn, T. A., Frindt, W., Gershon, R., Haythornthwaite, C., Kohler, T., Metz, J. M., and Sunder, S. 2001. Current new media research: An overview of communication and technology. In Communication yearbook, vol. 24. ed. W. Gudykunst, pp. 271-206. Mahwah, NJ: Lawrence Erlbaum Associates.

Lievrouw, L., and Livingstone, S., eds. 2002. Handbook of new media. London: Sage.
Lievrouw, L., Rogers, E. M., Lowe, C. U., and Nadel, E. 1987. Triangulation as a research strategy for identifying invisible colleges among biomedical scientists. Social Networks 9:217-248.

Rice, R. E., and Crawford, G. 1992. Context and content of citations between communication and library and information science articles. In Information and behavior, vol. 4, eds. J. Schement and B. Ruben, pp. 189-217. New Brunswick, NJ: Transaction Press.

Rice, R. E., and Danowski, J. 1993. Is it really just like a fancy answering machine? Comparing semantic networks of different types of voice mail users. Journal of Business Communication 30(4):369-397.

Savoy, J. 1992. Bayesian inference networks and spreading activation in hypertext systems. Information Processing and Management 28:389-406.

van Cuilenburg, J. J., Kleinnijenhuis, J., and de Ridder, J. 1986. A theory of evaluative discourse: Towards a graph theory of journalistic texts. European Journal of Communication 1:65-96.

Woelfel, J. 1991. CATPAC [Computer program]. Buffalo: New York State University, Department of Communication. 